\title{
POLÍTICAS PÚBLICAS DE INFORMAÇÃO E BIBLIOTECAS ESCOLARES: panorama brasileiro
}

\author{
Barbara Coelho Neves* \\ Niliane Cunha Aguiar
}

RESUMO

Palavras-chave: Políticas públicas. Política de Informação - Brasil. Bibliotecas Escolares.

\footnotetext{
* Doutora em Educação pela Universidade Federal da Bahia, Brasil. Professora do Instituto de Ciência da Informação da Universidade Federal de Sergipe, Brasil. Pesquisadora Líder do Laboratório de pesquisas em Tecnologias Informacionais e Inclusão Sociodigital - LTI.

E-mail: babi.coelho7@gmail.com.

** Mestre em Ciência da Informação pela Universidade Federal de Pernambuco, Brasil. Professora do Instituto de Ciência da Informação da Universidade Federal de Sergipe, Brasil. Doutoranda no Programa de Pós-Graduação em $\mathrm{Ci} \sim$ encia da Informação da Universidade Federal de Minas Gerais, Brasil. E-mail: nilianeaguiar@gmail.com.
}

\section{INTRODUÇÃO}

$\mathrm{P}$ ara levantar uma reflexão sobre a implementação de políticas públicas que possam atender a demanda da sociedade da informação, especialmente no que diz respeito às bibliotecas escolares, é preciso compreender que tal questão não está relacionada apenas à emergência de novas formas de produzir, distribuir e receber signos, mas é, sobretudo, um novo modo de nos definir, de ser, de estar e de nos relacionarmos com o mundo, como explicam Perrotti e Pieruccini (2013).

O contexto atual da sociedade demanda dos profissionais competências, habilidades e atitudes, para se relacionar como também para as atividades que envolvem ensino-aprendizagem e laborais. O profissional bibliotecário precisa estar atento a tais demandas e se familiarizar com as novas competências para operacionalizar, informar e participar como um dos elos essenciais nas atuais formas e ambientes de comunicar os conhecimentos.

Contudo, como explica Baptista, Noronha e Cruz (2013), para que isso aconteça, não basta assegurar materiais, tempos e espaços destinados à leitura, nem é suficiente, tampouco, a constituição de um acervo literário apropriado. Todos esses elementos são importantes, mas é primordial que, durante a educação básica, também seja iniciado o trabalho sistemático de letramento literário e informacional.

As políticas públicas de informação podem ser consideradas instrumentos de democratização do acesso à informação e ao conhecimento e ainda uma forma de legitimar a importância da biblioteca escolar para a construção dos rumos que essa sociedade, marcada pela produção, acesso e disseminação da informação, trilhará. Desse modo, dentre as definições de política pública de informação apresentadas neste texto, utiliza-se como perspectiva o entendimento de Braman (2011), considerando que a política 
de informação envolve aspectos relacionados ao acesso à informação governamental, a propaganda, a leis e regulação que convergem em toda a sociedade, nos processos da criação de informação, processamento, fluxos, acesso e uso.

\section{MÉTODO}

Para elaboração deste artigo de revisão de literatura utilizou-se como abordagem a perspectiva qualitativa, o método foi descritivo, a metodologia bibliográfica, com observação sistemática.

De acordo com a seleção de métodos aplicáveis aos trabalhos contextualizados na Ciência da Informação (MUELLER, 2007), as técnicas de pesquisa para a coleta de dados utilizadas nesta comunicação engendram-se no referencial teórico políticas públicas de informação. Como explanado anteriormente, a revisão da literatura contribuiu para uma compreensão acurada do tema no contexto da biblioteca escolar, assim como para delimitar os contornos epistemológicos assumidos. $\mathrm{O}$ arcabouço teórico se constitui elemento essencial para desenvolver as reflexões em torno desta problemática.

\section{POLÍtICAS PÚBLICAS DE INFORMAÇÃO}

A ciência política apresenta três abordagens de acordo com Frey (2000): em primeiro lugar, o questionamento clássico se refere ao sistema político e seu papel no Estado (polity); em segundo lugar, está o questionamento político que se refere à análise das forças políticas no processo decisório (politics) e por fim, estão as investigações voltadas para os resultados que um dado sistema político vem produzindo, cujo interesse primordial consiste na avaliação das contribuições que certas estratégias escolhidas podem trazer para a solução de problemas específicos (policy).

Política se define como sistema de regras que envolvem o Estado e a (res) pública ou coisa pública. É a esfera de atividades humanas que se referem de algum modo às coisas do Estado. (NEVES, 2017). Nesse contexto, trata-se de uma atividade, uma práxis, que envolve o poder do homem sobre outro homem.
Conforme Viana (2014), o termo política no idioma português, comporta as três acepções, o que por vezes pode dificultar a compreensão da terminologia, dado o entrelaçamento de suas dimensões conceituais. Compreendendo, portanto, a existência dessas dimensões: estrutural (sistema político), processual (processos políticos) e material (programas), pode-se dizer que é nessa última abordagem que se encontram as análises a respeito das políticas públicas.

De acordo com Souza (2006), não existe uma única, nem melhor, definição sobre o que seja política pública, assim, pode-se destacar como referência central para a análise desse trabalho, a síntese feita por Secchi (2010, p.1), que assim a define: política pública é uma diretriz elaborada para enfrentar um problema público.

Outras definições também são apresentadas por Souza (2006): a de Mead (1995), que a entende como um campo de estudo da política que analisa o governo à luz das grandes questões públicas; a de Lynn (1980), que a define como um conjunto de ações governamentais que produzem efeitos específicos; já para Peters (1986), é a soma das atividades dos governos que agem diretamente ou através de delegação e que influenciam a vida dos cidadãos e por fim Dye (1984), que sintetiza a definição de política pública como "o que o governo escolhe fazer ou não fazer". No Brasil, a expressão política pública começa a ser discutida a partir da década de 1970, substituindo, de certa forma, o espaço antes ocupado pela expressão "planejamento estatal" (FERREIRA, 2006 apud NEVES, 2010).

Howlett, Ramesh e Perl (2013, p. 6), por sua vez, afirmam que a política pública "[...] é um processo técnico-político que visa definir e compatibilizar objetivos e meios entre atores sociais sujeitos a restrições". Enquanto Jekins (1978), citado também por Howlett, Ramesh e Perl (2013, p. 8), define política pública como

[...] um conjunto de decisões interrelacionadas, tomadas por um ator ou grupo de atores políticos, e que dizem respeito à seleção de objetivos e dos meios necessários para alcançá-los, dentro de uma situação específica em que $\circ$ alvo dessas decisões estaria, em princípio, ao alcance desses atores. (JEKINS 1978 apud HOWELETT; RAMESH, PERL 20।3, p.8) 
Os atores das políticas públicas, isto é, os sujeitos que influenciam a elaboração e implementação dessas políticas, de acordo com Secchi (2010), são os indivíduos, grupos ou organizações que desempenham um papel na arena política, tais como os políticos, as empresas e as organizações não governamentais.

Dessa forma, resumidamente, é possível dizer que as políticas públicas podem ser vistas como um comportamento orientado para o alcance de objetivos específicos que resultam em decisões tomadas pelo governo.

Por esse motivo, ainda de acordo com Secchi (2010), foi desenvolvido um processo que organiza a vida de uma política pública em fases sequenciais e interdependentes, denominado "ciclo de políticas públicas" e sob tal concepção do ciclo de políticas, a política pública é vista como "[...] resultante de uma série de atividades políticas que, agrupadas, formam o processo político", explica Rua (2012, p.35).

Para Secchi (2010) o ciclo de políticas públicas possui sete fases principais: a) identificação do problema; b)formação da agenda; c) formulação de alternativas; d) tomada de decisão; e) implementação; f) avaliação; g) extinção.

Rua e Romani (2013) distinguem as políticas públicas de acordo com as suas características setoriais, que abrangem dinâmicas e agendas próprias para cada área e desse modo as classifica em:

a) políticas sociais: destinadas a promoção do exercício de direitos sociais, como educação, habitação, etc.;

b) políticas econômicas: objetivam gerir a economia interna e promover a inserção do país na economia externa. ex. política monetária e cambial;

c) políticas de infraestrutura: procuram assegurar as condições para a implementação e a execução das políticas econômicas e sociais: ex. política de transporte, mineração, saneamento básico, etc.

d) políticas de estado: visam garantir o exercício da cidadania, a ordem interna do estado, a defesa externa e todas as condições necessárias à soberania nacional. ex. política de direitos humanos, segurança pública, meio ambiente, etc.
É importante ressaltar, que existe uma diferença entre políticas públicas de Estado e políticas de governo: as políticas de Estado tratam de políticas mais permanentes, que ultrapassam o período de um governo. Em contraposição, as políticas de governo tendem a ser passageiras, sendo vigentes apenas durante o mandato de seus idealizadores.

Outra questão que merece destaque é a compreensão de que as políticas públicas são desenvolvidas através de: planos, programas, projetos, ações e atividades.

Quadro 1: Formas de apresentação das políticas públicas

\begin{tabular}{|c|c|}
\hline $\begin{array}{c}\text { POLÍTICAS } \\
\text { PÚBLICAS }\end{array}$ & FORMAS DE APRESENTAÇÃO \\
\hline PLANO & $\begin{array}{l}\text { O plano de acordo com Majone } \\
\text { e Wildavsky (1984) pode ser } \\
\text { entendido como um conjunto } \\
\text { de disposições que pretendem } \\
\text { funcionar como ponto de partida } \\
\text { para o processo de experimentação, } \\
\text { auxiliando a procura pela estratégia } \\
\text { que melhor se adaptará às } \\
\text { circunstâncias particulares. }\end{array}$ \\
\hline PROGRAMA & $\begin{array}{l}\text { O programa é um conjunto de } \\
\text { atividades "organizadas para serem } \\
\text { realizadas dentro de cronograma e } \\
\text { orçamento específicos disponíveis } \\
\text { para a implementação de políticas, } \\
\text { ou para a criação de condições } \\
\text { que permitam o alcance de metas } \\
\text { políticas desejáveis" (ALA-HARJA; } \\
\text { HELGASON, 2000, p.8). }\end{array}$ \\
\hline PROJETO & $\begin{array}{l}\text { O projeto por sua vez, conforme } \\
\text { Garcia (1997), é um instrumento } \\
\text { de planejamento para alcançar } \\
\text { os objetivos de um programa, } \\
\text { que envolvem um conjunto de } \\
\text { operações, limitadas no tempo, } \\
\text { das quais, pretende-se alcançar um } \\
\text { produto final que visa expandir e } \\
\text { aperfeiçoar as ações do governo. } \\
\text { E "quando essas operações se } \\
\text { realizam de modo contínuo ou } \\
\text { permanente, são denominadas de } \\
\text { atividades" (GARCIA, 1997, p. 6). }\end{array}$ \\
\hline AÇÕES & $\begin{array}{l}\text { Por fim, as ações, visam o alcance de } \\
\text { determinado objetivo estabelecido } \\
\text { pelo programa, e a atividade, } \\
\text { conforme, explica Pereira (2014) é o } \\
\text { que dá concretude à ação. }\end{array}$ \\
\hline
\end{tabular}

Fonte: Elaboração própria (2017). 
O entendimento dos conceitos de política pública pode, portanto, conforme explica Silva (2004), favorecer a percepção do problema para o qual a mesma foi estabelecida, de seus possíveis conflitos, da trajetória a ser seguida e principalmente do papel dos indivíduos, grupos e instituições que estão envolvidos na decisão e que certamente serão afetados por ela.

Desse modo, voltando-se para a questão informacional, é possível basear-se na ideia de Wersig e Neveling (1975, p.11) quando abordam os fenômenos de interesse para a Ciência da Informação, ressaltam o problema de transferência do conhecimento para aqueles que dele necessitam. Para os autores, isso é "[...] uma responsabilidade social e esta responsabilidade social parece ser o motivo real da ciência da informação".

É possível acreditar, portanto, que é a partir de tal responsabilidade, que as políticas públicas de informação podem se sustentar, preparando o Estado para as necessidades e demandas da sociedade da informação.

Neste contexto, as políticas públicas de informação podem ser consideradas ainda como uma decisão governamental, cuja responsabilidade está na regulação de todas as atividades e direitos do setor informacional conforme explicam Schwarzelmuller, Gesteira e Bulcão (2004).

O regime de informação é um dos aspectos relevantes, geralmente destacado nos estudos de política de informação, e que envolve o âmbito governamental. Tal regime mantém o domínio que reúne governo, governança e governabilidade, como destaca Braman (2006):

- Governo: instituições formais, regras, normas, práticas e histórias de entidades geopolíticas;

- Governança: instituições formais e informais, regras, acordos e práticas (ações e comportamentos) de atores estatais e não-estatais com efeito constitutivo na sociedade;

- Governabilidade: contexto social e cultural no qual modelos de governança emergem e são sustentados.

Se em conformidade com a afirmação de Castells (2000), a sociedade da informação é uma sociedade em rede e, portanto, plural nas suas formas de poder, é admissível que as transformações pelas quais essa sociedade passa, devido ao avanço tecnológico, também afetem as políticas públicas e novas estratégias tornam-se indispensáveis para orientar ações afirmativas no âmbito da informação.

A definição clássica restrita a política de informação envolve aspectos relacionados ao acesso à informação governamental, a propaganda, a leis e regulação. Segundo Braman (2011, tradução livre), o primeiro uso da expressão 'política de informação', por parte dos governos, se refere aos esforços de propaganda durante a Primeira Guerra Mundial.

A política de informação emerge como tema e domínio relativamente autônomo, em nível nacional e internacional, no cenário do pós-guerra, associada às políticas de ciência e tecnologia, de acordo com Gonzáles de Gomez (2002). Historicamente, no Brasil, o tema política de informação está ligado à Ciência e Tecnologia, sendo o Instituto Brasileiro de Informação em Ciência e Tecnologia (IBICT), o principal catalizador de ações e práticas voltadas para esse contexto, explica Neves (2016).

No Brasil, de acordo com Schwarzelmuller, Gesteira e Bulcão (2004), os anos 1950 marcam o surgimento das primeiras políticas de informação que focavam o crescimento científico e tecnológico. Na década de 1980, na América Latina, uma nova geração de políticos chega ao poder - Menen na Argentina, Salinas no México, José Sarney no Brasil, dentre outros - e assim há uma revisão da estratégia econômica e das políticas de informação e comunicação, conferindo novos rumos dessas políticas com as relações sociais e entre Estado e sociedade, relata Neves (2010).

Atualmente, segundo Schwarzelmuller, Gesteira e Bulcão (2004), as propostas de implementação de políticas públicas de informação brasileiras carecem de articulação entre as esferas cultural, educacional e de comunicação que se entrelaçam com as relações socioeconômicas, e por esse motivo devem ser flexíveis o bastante para permitir a participação dos mais diversos setores da sociedade brasileira.

Nesse contexto, as iniciativas não devem partir unicamente do Estado, mas também da atuação da sociedade civil em torno de suas necessidades para viabilizar a elaboração e a prática de políticas de informação que promovam seu desenvolvimento científico, cultural e social. 
A partir desse entendimento, e em concordância com Silva (1991, p.12) entende-se que as políticas públicas que privilegiam a importância da informação, contribuem "[...] para a melhoria do nível educacional, cultural e político, elementos básicos para o exercício pleno da cidadania".

A esse respeito, num contexto geral, de acordo com Schwarzelmuller, Gesteira e Bulcão (2004) nos últimos anos é possível destacar no Brasil, algumas importantes medidas: criação do Programa Nacional de Incentivo à Leitura Proler (1992); Programa Sociedade da Informação (2000); criação da Política Nacional do Livro (2003) e a criação do programa Fome de Livro (2004).

\section{POLÍTICAS DE INFORMAÇÃO PARA BIBLIOTECAS ESCOLARES}

Inserida neste contexto informacional e social, a biblioteca escolar, também necessita da atuação das políticas públicas para o desenvolvimento de suas atividades, pois "[...] somente o estado pode assegurar a universalização dos direitos à cultura e à informação para a população [...]" e por esse motivo, as políticas públicas devem propiciar ao cidadão uma melhoria de vida na área educacional, social e cultural, promovendo a transformação da realidade do povo (FURTADO, 2011, p. 2).

Desse modo, e para a mesma autora, as políticas públicas instituem oportunidades dos diversos grupos excluídos socialmente exercerem a sua cidadania e serem favorecidos por ações democráticas e libertadoras capazes de valorizar esses indivíduos, proporcionando a igualdade de acesso aos meios e bens culturais.

Sobre a intenção de participação da sociedade no contexto das políticas públicas, Cunha (2006, p. 2) aborda que os resultados do processo de transição política a partir da saturação do regime militar instalado em 1964 no Brasil têm colocado os conceitos de "[...] democracia e descentralização no centro das discussões políticas e acadêmicas, ratificandoos como valores necessários à cristalização dos ideais de participação da sociedade na formulação e execução das políticas públicas".
Porém, como explica Viana (2014), a biblioteca escolar ainda pode ser considerada um problema público, visto que se no século XIX, resumia-se a um acervo de materiais para leitura, em pleno século XXI ainda é visualizada de modo semelhante nos textos legislativos que ressaltam a disponibilidade de seus recursos informacionais, como se tal fornecimento caracterizasse por si só uma biblioteca escolar.

As bibliotecas escolares, tais como são conhecidas hoje, são relativamente recentes na história brasileira. De acordo com Silva (2011), somente a partir de 1870 as escolas particulares passaram o desenvolver acervos gerais e não mais especificamente religiosos como as bibliotecas dos colégios católicos, passando a oferecer materiais científicos e materiais de variadas denominações religiosas, tornando a biblioteca escolar um espaço de aprendizagem mais democrático.

Apesar da constituição de 1824 garantir que a educação seria um direito de todos (BRASIL, 1824), foi somente nos anos de 1930 que o Governo Federal Varguista através do Ministério da Educação comandado por Gustavo Capanema, iniciou a apresentação de alguns marcos legislativos salutares para o desenho da biblioteca nas gestões públicas, explica Oliveira (2013).

Contudo, algumas iniciativas isoladas foram realizadas principalmente no Distrito Federal e também no Rio de Janeiro, que pelo Decreto 2940, de 29 de novembro de 1928, determinava que todas as escolas do Rio de Janeiro deveriam possuir duas bibliotecas, uma para alunos e outras para os professores. Este decreto ainda estipulou o cargo de bibliotecário, que seria o responsável pela conservação dos livros, organização do catálogo, elaboração de relatórios sobre a movimentação da biblioteca e atendimento aos professores e alunos, relata Vidal (2000 apud ALONSO, 2007).

Silva (2011) também destaca o estado de Santa Catarina nas décadas de 1940 a 1950 como referência para a instituição de procedimentos legais e pedagógicos para a instalação de bibliotecas, mostrando que a Secretaria da Educação e Saúde de Santa Catarina já em 1943 estabelecia critérios para as coleções de suas bibliotecas escolares.

Com a criação de um Plano Nacional de Educação, a obrigatoriedade e gratuidade 
do ensino básico, a regulamentação do ensino primário, secundário e o ensino da língua portuguesa, a leitura passa a ser escolarizada de modo mais formal e surgem programas para a distribuição de livros pelo Instituto Nacional do Livro (INL), e a Constituição Federal de 1934 apresenta um capítulo exclusivo para a educação, conforme explicam Oliveira e Adrião (2007).

Tal manifesto repercute com a inserção do artigo 150 da Constituição Federal de 1934, indicando a necessidade de estabelecer um plano de educação para todos os níveis e em todos os estados do país. Cria-se, assim, um primeiro documento nomeado como Plano Nacional de Educação (PNE), reformulado em 1965, estabelecendo, às esferas estaduais e municipais, direcionamentos para a educação brasileira, conforme explica Oliveira (2013).

Desse modo, de acordo com Silva (2011, p.497), observa-se no período de 1930 até a década de 1980, a falta de uma “[...] política nacional específica para bibliotecas" e assim, em 1944, Lourenço Filho pertencente ao movimento da Escola Nova, iniciado em 1932, manifesta o seu entendimento sobre o papel da biblioteca escolar no processo educativo e afirma que "[...] uma escola sem biblioteca é um instrumento imperfeito." (LOURENÇO FILHO, 1944, p.4 citado por ALONSO, 2007).

A primeira Lei de Diretrizes e Bases (LDB) brasileira data de 1961, estabelecida pela lei n. 4024 de 20 de dezembro de 1961 e surge na intenção de descentralizar o ensino, atribuindo responsabilidades e colaborações entre os estados e municípios, explicam Haidar e Tanuri (2004). De acordo com as autoras, outra lei que pode ser considerada importante para o segmento da biblioteca escolar, foi a Lei 4.084 de junho de 1962, que regulamentou o exercício do profissional bibliotecário brasileiro, apesar de ainda não garantir a exclusividade de sua atuação nas bibliotecas escolares.

Oliveira (2013) acrescenta, porém, que durante a ditadura militar iniciada no golpe de 1964, as políticas de livro e leitura são diretamente impactadas pela censura do Estado e desse modo a educação e, por consequência, as bibliotecas, sofrem uma forte repressão com tal mudança política. Ainda nesse período de censura, o Ministério da Educação (MEC) cria em 1966 uma Comissão do Livro Técnico e Livro Didático (COLTED), com o objetivo de coordenar as ações referentes à produção, edição e distribuição do livro didático.

Em 1968 foi criada a Fundação Nacional do Livro Infantil e Juvenil (FNLIJ), que segundo Perrotti (1990) visava promover o livro, a leitura e a literatura infantojuvenil. A trajetória da FNLIJ, segundo o autor, foi marcada por um reconhecimento internacional no ano de 1984, ao receber uma menção honrosa do prêmio Iraque de alfabetização, realizado pela Organização das Nações Unidas para Educação, Ciência e Cultura (UNESCO).

De acordo com Campello (2003), a promulgação da Lei 5692 de 11 de agosto de 1971, que modificou a LDB de 1961 e fixou as diretrizes e bases para o ensino de $1^{\circ}$ e $2^{\circ}$ graus, entusiasmou os bibliotecários com as novas possibilidades de ação, que se apressavam na tentativa de reforçar o fato de que a nova concepção de aprendizagem não poderia ignorar a contribuição da biblioteca. Porém, o avanço não foi como esperado, pois na contramão dessa expectativa, devido à questão política brasileira, de acordo com Alonso (2007, p.45), foi deliberado o decreto Lei 1.070 de 06 de janeiro de 1971, determinando que a leitura, acesso e o acervo de bibliotecas deveriam ficar a disposição da Polícia Federal que analisaria a existência de materiais que pudessem ofender a moral e os bons costumes.

Sendo assim, somente com a reabertura democrática, marcada pelo Constituição de 1988, a educação volta a apresentar um discurso mais universalizante, marcado pelo caráter ideológico liberal, buscando atender à demanda do mercado, explica Oliveira (2013).

Outro marco legislativo para a educação brasileira se deu com a Lei 9.394/96 - Lei de Diretrizes e Bases da Educação Nacional, que subordinada a Constituição de 1988, estabeleceu de forma específica os rumos que ainda hoje estruturam a atual organização do sistema educacional brasileiro.

Em seguida, no ano de 1997 estabelecemse os Parâmetros Curriculares Nacionais (PCNs) que de acordo com Silva (2011), contemplam o discurso da biblioteca escolar como espaço de estímulo à leitura e aprendizado.

No mesmo ano, destaca-se a criação do Programa Nacional Biblioteca na Escola (PNBE), cuja principal missão seria a distribuição de livros e não uma política mais ampla para a 
biblioteca escolar, deixando que em muitas escolas tais livros fossem perdidos por falta de local e tratamento adequado, explica Garcez (2007, p. 28).

Conforme mostra Pereira (2006), o interesse de auxiliar os trabalhos das bibliotecas escolares brasileiras, fez com que em 1998, o Ministério da Educação e o Fundo Nacional de Desenvolvimento da Educação apresentassem dois manuais: o manual da biblioteca da escola e o manual pedagógico da biblioteca da escola.

Também em 1998, outra lei oferece sua contribuição para a área da Biblioteconomia, e consequentemente para a biblioteca escolar: a Lei $n^{\circ}$ 9.674, de 26 de junho de 1998, que dispõe sobre o exercício da profissão de bibliotecário e determina outras providências (BRASIL, 1998).

Em 1999, a Federação Internacional de Associações de Bibliotecários e Instituições (IFLA) e a UNESCO aprovaram o Manifesto da Biblioteca Escolar intitulado "A biblioteca escolar no ensino e aprendizagem para todos", que ofereceu grande contribuição para a reflexão sobre as políticas públicas para bibliotecas escolares também no Brasil.

No entanto, a principal legislação referente à biblioteca escolar brasileira foi iniciada a partir da publicação do Projeto de Lei 3549/2000 apresentado no dia 14 de setembro de 2000, que pretendendo contribuir com a discussão sobre o ato da leitura, apresentou uma definição para biblioteca escolar, caracterizando-a como "[...] a coleção de livros, materiais videográficos e documentos congêneres para estudo, consulta e leitura recreativa, considerando como acervo mínimo quatro livros por aluno matriculado" (BRASIL, 2000).

Em 2001 a Lei Federal 10172 de 09 de janeiro, aprovou o Plano Nacional de Educação (PNE), um plano de estado e não de governo, com duração de dez anos (2001 a 2010), que apesar de não mencionar especificamente o papel da biblioteca escolar, objetiva a elevação do nível de escolaridade da população; melhoria da qualidade da educação; democratização educacional, em termos sociais e regionais e a democratização da gestão do ensino público (BRASIL, 2001).

Em 2003, a Lei 10.753 de 30 de outubro, institui a política nacional do livro - PNL, mencionando a biblioteca escolar em seu terceiro capítulo e responsabilizando o poder executivo pela criação anual de programas para a manutenção e atualização do acervo (BRASIL, 2003).

Cinco anos após a aprovação do Manifesto da Biblioteca Escolar, a IFLA e a UNESCO estabelecem as diretrizes para a biblioteca escolar, objetivando informar os tomadores de decisão e dar suporte à comunidade bibliotecária, auxiliando as escolas que se encontram em processo de implementação (IFLA; UNESCO, 2005).

Buscando oferecer sua contribuição para o panorama brasileiro, o Conselho Federal de Biblioteconomia, (CFB) junto aos Conselhos Regionais de Biblioteconomia (CRB), elaborou em 2008, um projeto mobilizador para sensibilizar a sociedade e os bibliotecários para a promoção da qualidade no ensino público através da criação e implantação de uma rede de bibliotecas escolares, dinâmica e eficaz (CFB; CRB, 2008).

Ainda em 2008, a redação do projeto de Lei 3044/2008 de autoria do deputado federal Sandes Junior (BRASIL,2008), propõe a alteração da Lei $n^{\circ}$ 9.394, de 20 de dezembro de 1996 - Lei de Diretrizes e Bases da Educação Nacional, para instituir a obrigatoriedade de criação e manutenção de bibliotecas escolares em todas as instituições públicas de ensino.

No entanto, o mesmo deputado, apresenta em 24 de abril 2012, o projeto de Lei 28/2012, no qual propõe a inserção de dois artigos (27a e 27-b) na LDB que excluem as bibliotecas escolares da rede particular de ensino e viabiliza para o empregador a possibilidade de contratar um bibliotecário para atuar em mais de uma biblioteca sem definir o número máximo de estabelecimentos que um profissional poderá atuar, causando um descontentamento na classe bibliotecária (BRASIL, 2012). O projeto ainda está em tramitação, e encontra-se em fase de análise na Comissão de Educação, Cultura e Esporte (Secretaria de Apoio à Comissão de Educação, Cultura e Esporte), tendo sido analisado pela última vez em 12 de março de 2015, de acordo com o site do Senado Federal.

De acordo com Oliveira (2013), em 20 de dezembro de 2010 ocorre a apresentação do Projeto de Lei 8035/2010, que aprova o Plano Nacional de Educação (PNE) para o decênio 2011-2020, sendo composto, composto de 10 diretrizes e 20 metas, ele demonstrou força de lei e utilizou os indicadores do índice de 
desenvolvimento da educação básica (IDEB) para o estabelecimento de metas através dos números do índice. Este projeto de lei depois da tramitação levou a aprovação do PNE em 2014 através da Lei 13.005 de 25 de junho. Esse aspecto será tratado com mais detalhe mais a diante neste texto, visando apontar se este PNE trata das bibliotecas escolares dentre suas estratégias.

Também em 2010, especificamente no dia 25 de maio, a mesa diretora da Câmara dos Deputados publicou no Diário Oficial da União a Lei ordinária 12.244/2010, que dispõe sobre a universalização das bibliotecas nas instituições de ensino no país (BRASIL, 2010), contando com quatro artigos e um parágrafo único, "construídos em nove anos e oito meses de tramitação, desde a sua publicação como PL359/2000", ressalta Oliveira (2013, p. 81).

No primeiro artigo da lei ficou esclarecido que, as instituições de ensino regidas pela lei, pertencem à educação básica, visto que na LDB fica expresso que a educação superior é ministrada em instituições de ensino superior. No segundo artigo da lei, apresenta-se a definição de biblioteca e determina a quantidade de um título para cada aluno da escola, proposto no parágrafo único.

Ainda no parágrafo único fica expressa a responsabilidade de desenvolvimento do acervo aos sistemas de ensino conforme a realidade de cada um e dispõe orientações de guarda, preservação, organização e funcionamento das bibliotecas.

O texto do terceiro artigo apresenta a obrigação dos sistemas de ensino em desenvolver a universalização das bibliotecas escolares no prazo máximo de 10 anos, respeitando a profissão do bibliotecário, conforme a regulamentação e conselho competente e por fim, o quarto artigo decreta o vigor da lei a partir da data de sua publicação (BRASIL, 2010).

Além dessa lei específica, sabe-se que em todo país, há inúmeros esforços individuais e coletivos, por meio de instituições, sindicatos e associações, que compreendem a importância da biblioteca escolar no processo de ensino e aprendizagem. Dentre os quais se pode destacar no Brasil, o trabalho desenvolvido pelo Grupo de Estudos em Biblioteca Escolar, como explica Campello (2010). Pertencente à Escola de Ciência da Informação da Universidade Federal de Minas Gerais (UFMG), esse Grupo ofereceu uma publicação com os padrões para criação e avaliação de bibliotecas escolares, que posteriormente se tornou uma resolução do Conselho Federal de Biblioteconomia (CFB, 2011) 119 de 15 de julho de 2011, estabelecendo os Parâmetros para as Bibliotecas Escolares brasileiras sendo publicada no Diário Oficial da União de 18/07/2011, nas páginas 193 e 194.

Por esse motivo não se pode estacionar nas dificuldades existentes, mas ao contrário, precisamos destacar os casos de sucesso que podem ser observados na Rede Escolar de Bibliotecas Interativas da cidade de São Bernardo do Campo (VIANA, 2014), que apresentou resultados concretos e inovadores de gestão e organização, alcançando a admiração de alunos, pais e da comunidade em geral; no Sistema Estadual de Bibliotecas de Goiás (FIALHO et al, 2013) que administra de modo eficiente todas as bibliotecas escolares do Estado de Goiás e que por meio de audiência pública inseriu o conceito de biblioteca escolar na Resolução n. 05, de 10 de junho de 2011 do Conselho Estadual de Educação e no Sistema Estadual de Bibliotecas escolares do Rio Grande do Sul (VIEIRA, 2012), que foi legitimado desde 1989 e até hoje se responsabiliza pela integração, coordenação e fomentação do desenvolvimento dos serviços bibliotecários no Estado do Rio Grande do Sul.

Em 2014, a Lei 13.005 aprova o Plano Nacional de Educação, em de 25 de junho. Prevê a construção, planejamento e metas para implementação de políticas públicas educacionais nacionais no período de vigência de 10 anos (2014 a 2024). A previsão de avaliação do PNE, com relação as suas metas, ficou prevista para o quarto ano de sua vigência, ou seja em 2017. Desse modo, no tocante a biblioteca escolar, destaca-se a Meta 16 do PNE, que visa:

\footnotetext{
Garantir, em regime de colaboração entre a União, os Estados, o Distrito Federal e os Municípios, no prazo de I (um) ano de vigência deste PNE, política nacional de formação dos profissionais da educação de que tratam os incisos I, II e III do caput do art. 6I da Lei no 9.394, de 20 de dezembro de 1996, assegurado que todos os professores e as professoras da educação básica possuam formação específica de nível superior, obtida em curso de licenciatura na área de conhecimento em que atuam (BRASIL, 20I6).
} 
Para tanto, a estratégia da meta 16 pretende implantar, no prazo de 1 (um) ano de vigência desta Lei, política nacional de formação continuada para os (as) profissionais da educação de outros segmentos que não os do magistério, construída em regime de colaboração entre os entes federados. Neste ponto inclui como previsão de formação, dentre outros, também o envolvimento do Programa Nacional Biblioteca da Escola (PNBE).

Também percebe-se o envolvimento e importância da biblioteca escolar, em estratégias das metas 6, 7, 16 e 19, conforme detalhado por Silva e Cunha (2016) no quadro 2.

Quadro 2: Biblioteca escolar no PNE 2016

\begin{tabular}{|c|c|c|c|}
\hline METAS & ESTRATÉGIAS & META & ESTRATÉGIAS \\
\hline $\begin{array}{l}\text { Meta 6: oferecer educação em } \\
\text { tempo integral em, no minimo, } 50 \% \\
\text { (cinquenta por cento) das escolas } \\
\text { públicas, de forma a atender, pelo } \\
\text { menos, 25\% (vinte e cinco por } \\
\text { cento) dos (as) alunos (as) da } \\
\text { educação básica. }\end{array}$ & $\begin{array}{l}\text { - Institucionalizar e manter, em regime de } \\
\text { colaboração, programa nacional de } \\
\text { ampliaçao e reestruturaçăo das escolas } \\
\text { públicas, por meio da instalaçåo de } \\
\text { quadras poliesportivas, laboratórios, } \\
\text { inclusive de informática, espaços para } \\
\text { atividades culturais, bibliotecas, auditórios, } \\
\text { cozinhas, refeitórios, banheiros e outros } \\
\text { equipamentos, bem como da produçăo de } \\
\text { material didático e da formação de recursos } \\
\text { humanos para a educaçăo em tempo integral; } \\
\text { - Fomentar a articulaçăo da escola com os } \\
\text { diferentes espaços educativos, culturais e } \\
\text { esportivos e com equipamentos públicos, } \\
\text { como centros comunitários, bibliotecas, } \\
\text { praças, parques, museus, teatros, cinemas e } \\
\text { planetários; }\end{array}$ & $\begin{array}{l}\text { Meta 16: formar, em nível de } \\
\text { pós-graduação, } r 50 \% \\
\text { (cinquenta por cento) dos } \\
\text { professores da educação } \\
\text { básica, até o último ano de } \\
\text { vigência deste PNE, e garantir } \\
\text { a todos (as) os (as) } \\
\text { profissionais da educação } \\
\text { básica formaça continuada } \\
\text { em sua área de atuação, } \\
\text { considerando as necessidades, } \\
\text { demandas e contextualizações } \\
\text { dos sistemas de ensino. }\end{array}$ & $\begin{array}{l}\text { - Expandir programa de composição de acervo de } \\
\text { obras didáticas, paradidáticas e de literatura e de } \\
\text { dicionários, e programa específico de acesso a bens } \\
\text { culturais, incluindo obras e materiais produzidos em } \\
\text { Libras e em Braille, sem prejuízo de outros, a serem } \\
\text { disponibilizados para os professores e as } \\
\text { professoras da rede pública de educação básica, } \\
\text { favorecendo a construção do conhecimento e a } \\
\text { valorização da cultura da investigação; } \\
\text { - Fortalecer a formação dos professores e das } \\
\text { professoras das escolas públicas de educação básica, } \\
\text { por meio da implementação das ações do Plano } \\
\text { Nacional do Livro e Leitura e da instituição de } \\
\text { programa nacional de disponibilização de recursos } \\
\text { para acesso a bens culturais pelo magistério público. }\end{array}$ \\
\hline $\begin{array}{l}\text { Meta 7: fomentar a qualidade da } \\
\text { educação básica em todas as etapas } \\
\text { e modalidades, com melhoria do } \\
\text { fluxo escolar e da aprendizagem de } \\
\text { modo a atingir em } 2021 \text { as médias } \\
\text { nacionais para o IDEB } 6,0 \text { para os } \\
\text { anos iniciais do ensino } \\
\text { fundamental, 5,5, para os anos } \\
\text { finais do ensino fundamental e } 5,2\end{array}$ & $\begin{array}{l}\text { - Prover equipamentos e recursos tecnológicos } \\
\text { digitais para a utilizaçấo pedagógica no } \\
\text { ambiente escolar a todas as escolas públicas } \\
\text { da educaça básica, criando, inclusive, } \\
\text { mecanismos para implementação das } \\
\text { condiçōes necessárias para a } \\
\text { universalização das bibliotecas nas } \\
\text { instituições educacionais, com acesso a } \\
\text { redes digitais de computadores, inclusive a } \\
\text { internet; } \\
\text { - Promover, com especial ênfase, em } \\
\text { consonância com as diretrizes do Plano } \\
\text { Nacional do Livro e da Leitura, a formaçấo de }\end{array}$ & $\begin{array}{l}\text { Meta 19: Assegurar condições, } \\
\text { no prazo de } 2 \text { (dois) anos, para } \\
\text { a efetivaçă da gestão } \\
\text { democrática da educação, } \\
\text { associada a critérios técnicos } \\
\text { de mérito e desempenho e à } \\
\text { consulta pública à comunidade } \\
\text { escolar, no âmbito das escolas } \\
\text { públicas, prevendo recursos e } \\
\text { apoio técnico da União para } \\
\text { tanto. }\end{array}$ & $\begin{array}{l}\text { - Estimular a participação e a consulta de } \\
\text { profissionais da educação, alunos (as) e seus } \\
\text { familiares na formulação dos projetos político- } \\
\text { pedagógicos, currículos escolares, planos de gestão } \\
\text { escolar e regimentos escolares, assegurando a } \\
\text { participação dos pais na avaliação de docentes e } \\
\text { gestores escolares; }\end{array}$ \\
\hline para o ensino médio. & $\begin{array}{l}\text { leitores e leitoras e a capacitação de } \\
\text { professores e professoras, bibliotecários e } \\
\text { bibliotecárias e agentes da comunidade para } \\
\text { atuar como mediadores e mediadoras da } \\
\text { leitura, de acordo com a especificidade das } \\
\text { diferentes etapas do desenvolvimento e da } \\
\text { aprendizagem; }\end{array}$ & & \\
\hline
\end{tabular}

Fonte: Silva e Cunha (2016).

É possível perceber que a referencias às bibliotecas escolares aparece nas metas $\mathrm{e}$ estratégias do PNE de forma indireta.

De acordo com Silva e Cunha (2016), outra estratégia instituída pelo PNE para o alcance da décima sexta meta, é necessário fomentar a capacitação de professores e professoras em atividades do Plano Nacional do Livro e da Leitura (PNLL). Tais iniciativas estão contribuindo para efetivar o papel das bibliotecas escolares e para valorizar sua importância no contexto brasileiro.

\section{CONSIDERAÇÕES FINAIS}

Diante do exposto, é possível concordar com Castro Filho e Coppola Júnior (2012, p.39) quando acreditam que a Lei n. ${ }^{\circ}$ 12.244/2010 representa um dos maiores avanços, no sentido do Estado se posicionar frente ao Manifesto da IFLA/UNESCO para biblioteca escolar. Porém, os autores ainda ressaltam que cabe à comunidade escolar, aos professores, aos bibliotecários, reivindicar a aplicação desta lei, de forma a impedir que seja esquecida e suprimida por outros interesses.

Agora a biblioteca escolar subsidiada pelas leis e projetos apresentados, encontra novas motivações para avançar, e os próximos passos provavelmente serão voltados a criação de sistemas estaduais e municipais de bibliotecas escolares, a exemplo do Rio Grande do Sul que já está amparado pela Lei 8.744 de 9 de novembro de 1988 e do Rio de janeiro pelo Projeto de Lei $n^{\circ}$ 903/2015. 
O que se espera é desenvolver a biblioteca escolar para que alcancem patamar daquilo que Perrotti e Pieruccinni (2008) entendem como biblioteca escolar: uma unidade de informação de estabelecimento de ensino, que tem em vista a contribuição para a melhoria do ensino público e da apropriação cultural, por meio do desenvolvimento de novos conceitos de serviços de informação em educação, entendendo seus usuários como protagonistas culturais.

Sendo assim, é possível observar que, mesmo sem a utilização específica do termo biblioteca escolar, a legislação brasileira apresenta espaço para a atuação dessas unidades de informação, nos rumos da Educação no Brasil, e diante dessa realidade, as discussões continuam:

a) através do Projeto de Lei 3088/2012 de autoria do Senador Paulo Bauer (PSDB/ SC) que objetiva regular o programa de seleção, aquisição e distribuição de material didático para a educação básica do Programa Nacional do Livro Didático (PNLD);

b) do Projeto de Lei 5808/2013 de autoria do Deputado Federal Valadares Filho (PSB/ $\mathrm{SE})$ que pretende regular a alocação de recursos para atualização de acervos das bibliotecas públicas nas esferas municipais, estaduais, federais e do Distrito Federal, como também das unidades de informação universitárias, escolares e as pertencentes a organizações não governamentais;

c) do Projeto de Lei do Senador Cristovam Buarque, 28/2015 que pretende instituir a Política Nacional de Bibliotecas; d) e do Projeto de Lei do deputado Flávio Serafini (PSOL/RJ), 597/2015 que institui o sistema estadual de bibliotecas escolares do estado do Rio de Janeiro (SEBE - RJ).

A expectativa é mesmo, que tais discussões, associadas à efetivação da Lei 13.005-2014, que institui Plano Nacional de Educação, com metas decenais, prossigam rumo ao desenvolvimento de bibliotecas escolares de excelência, capazes de cumprir sua função educacional, social e cultural na sociedade contemporânea.

Prevalece, portanto, a necessidade de reflexão sobre os melhores instrumentos a serem utilizados para promover o avanço das políticas públicas de informação no Brasil e cabe a todos os interessados, uma pausa para a avaliação e monitoramento das políticas existentes, entendendo que o exercício de tal mensuração não resulta apenas de uma necessidade científica, mas objetiva dar significado à complexidade dos fenômenos.

Desse modo, espera-se que as futuras políticas públicas de informação no Brasil sejam sustentadas pela demanda da atual sociedade, fortalecendo o letramento informacional que deve ser iniciado na biblioteca escolar, abrangendo, além das questões cognitivas e educacionais, outras questões como a inclusão digital, conceitos de transferência de informação, acesso e domínio das tecnologias de informação e comunicação (TIC), promoção da cidadania, apropriação e protagonismo cultural e competência informacional. Tais questões, devem se aliar à conscientização por parte de todos os interessados pela biblioteca escolar, mobilizando-os para exigir que se cumpra o papel que o estado possui de promovê-las por meio de políticas públicas.

\section{Artigo recebido em I3/03/2017 e aceito para publicação em 10/II/2017}

\section{PUBLIC POLICY INFORMATION AND LIBRARIES SCHOOL: Brazilian panorama}

ABSTRACT The study presents a survey of public information policy in Brazil that offered contributions to the field of school librarianship. Through literature and systematic observation, it proposes reflections on the theoretical aspects covering concepts related to public policy information and highlights the panorama of Brazilian public policy information that are under development. Proposes examination of the thematic interested public policies of information and library science school about the necessary mobilization of these, both for the promotion and development of such policies, as to the claims of full implementation for the benefit of society.

Keywords: $\quad$ Public Policies. Information Policies - Brazil. School Library. 


\section{REFERÊNCIAS}

ALA-HARJA, M.; HELGASON, S. Em direção às melhores práticas de avaliação. Brasília, DF, Revista do Serviço Público, v. 51, n. 4, out./dez., 2000.

ALONSO, C. M. R. Biblioteca escolar: um espaço necessário para a leitura na escola. Dissertação (Mestrado em Educação) - Faculdade de Educação, Universidade de São Paulo, 2007. Disponível em: <http://www.teses.usp.br/ teses / disponivesi / 48/48134/tde_17122009080005/pt-br.php>. Acesso em 08 jan. 2016.

BAPTISTA, M. C.; NORONHA, A. A.; CRUZ, P. M. C.. Letramento literário na primeira infância. In.: COLÓQUIO DE ESTUDOS EM NARRATIVA., 1，2013, Uberlândia. Anais... Uberlândia: EDUFU, 2013. Disponível em:<http:/ / www.ileel.ufu.br/anaisdocena/wpcontent/uploads/2014/02/cena3_artigo_5.pdf>. Acesso em 10 jan.2016.

BRAMAN, S. Change of state: information, policy and power. Cambridge: Mit Press, 2006.

A Economia Representacional e o regime Global da Política de informação. In: MACIEL, M.L. ALBAGLI, S. (ORGS.) Informação, Conhecimento e Poder: mudança tecnológica e inovação social. Rio de Janeiro: Garamond, cap.2, p.41-66, 2011.

BRASIL. Constituição (1824). Constituição da República Federativa do Brasil: promulgada em 25 de março de 1824. Brasília: Congresso Nacional,1824. Disponível em: <http://www.planalto.gov.br/ ccivil_03/Constituição/Constitui\%C3\%A7ao24. htm>. Acesso em 08 an. 2016.

BRASIL. Lei n. 9.674, de 26 de junho de 1998. Dispõe sobre o exercício da profissão de Bibliotecário e determina outras providências. Brasília: Congresso Nacional,1998. Disponível em: <http://www.planalto.gov.br/ccivil_03/ leis/L9674.htm>. Acesso em 09 jan. 2016.

BRASIL. Lei n.10172 de 09 de janeiro de 2001. Aprova o Plano Nacional de Educação e dá outras providências. Brasília: Congresso Nacional,2001. Disponível em: <http://www. planalto.gov.br/ccivil_03/leis/leis_2001/110172. htm>. Acesso em 09 jan. 2016.

BRASIL. Lei 10.753 de 30 de outubro de 2003 . Institui a Política Nacional do Livro. Brasília: Congresso Nacional,2003. Disponível em: <http:/ / www.planalto.gov.br/ccivil_03/ leis/2003/L10.753.htm>. Acesso em: 09 jan. 2016.

BRASIL. Lei n. $^{\circ} \mathbf{1 2 . 2 4 4}$ de 24 de maio de 2010: dispõe sobre a universalização das bibliotecas nas instituições de ensino do País. Brasília: Congresso Nacional, 2010.

BRASIL. Projeto de Lei 3549, de 14 de setembro de 2000. Dispõe sobre a universalização das bibliotecas escolares e determina outras providências. Brasília: Congresso Nacional, 2000. Disponível em: <http:// www.camara.gov.br/proposicoesWeb/ prop_mostrarintegra;jsessionid $=378 \mathrm{C} 0 \mathrm{~A} 7956263$ 2C6F92069A130A7DCA7.proposicoesWeb1? codteor $=1121556 \&$ filename $=$ Dossie + -PL $+3549 /$ 2000>. Acesso em 09 jan. 2016.

BRASIL. Projeto de lei 3044/2008. Dispõe sobre a universalização das bibliotecas escolares e determina outras providências. Brasília: Congresso Nacional,2008. Disponível em: <http://www.camara.gov.br/proposicoesWeb/ prop_mostrarintegra?codteor $=545695 \&$ filenam $\mathrm{e}=$ Tramitacao-PL+3044/2008>. Acesso em 10 jan.2016.

BRASIL. Projeto de lei 28 de 24 de abril de 2012. Altera a Lei $\mathrm{n}^{\circ} 9.394$, de 20 de dezembro de 1996 - Lei de Diretrizes e Bases da Educação Nacional, para instituir a obrigatoriedade de criação e manutenção de bibliotecas escolares em todas as instituições públicas de ensino. Brasília: Congresso Nacional, 2012. Disponível em: <http://legis.senado.leg.br/mateweb/arquivos/ mate-pdf/106924.pdf>. Acesso em 10 jan. 2016.

CAMPELLO, B. A função educativa da biblioteca escolar no Brasil: perspectivas para seu aperfeiçoamento. In: ENCONTRO NACIONAL DE PESQUISA EM CIÊNCIA 
DA INFORMAÇÃO, 5., 2003, Belo Horizonte. Anais ... Belo Horizonte: Escola de Ciência da Informação da UFMG, 2003.

(Coord). Biblioteca escolar como espaço de produção do conhecimento: parâmetros para bibliotecas escolares. Belo Horizonte: UFMG/ ECI/GEBE; Autêntica. 2010. Disponível em: . Acesso em: 10 mai. 2012.

SILVA, J. L. C. Perspectivas históricas da biblioteca escolar no Brasil: análise da Lei 12.244/2010 que dispõe sobre a universalização das bibliotecas escolares. Revista ACB: Biblioteconomia em Santa Catarina, Florianópolis, v.16, n.2, p.489-517, jul./dez. 2011.

CASTELLS, M. A era da informação: economia, sociedade e cultura. 4. ed. São Paulo: Paz e Terra, 2000 .

CASTRO FILHO, C. M. de; COPPOLA JUNIOR, C.. Biblioteca escolar e a lei 12.244/2010: caminhos para implantação. Bibl. Esc. em Rev., Ribeirão Preto, v. 1, n. 1, p. 30-41, 2012.

CFB - CONSELHO FEDERAL DE BIBLIOTECONOMIA. Resolução 119 de 15 de julho de 2011. Dispóe sobre os parâmetros para as bibliotecas escolares. Brasília: CFB, 2011. Disponível em: < http://www.cfb.org. br/projetos.php? codigo $=22>$. Acesso em 10 jan. 2016.

CRB - Conselho Regional de Biblioteconomia. Projeto mobilizador: biblioteca escolar: construção de uma rede de Informação para o ensino público. Brasília: CFB/CRB, 2008.

CUNHA, M. C. A descentralização da gestão da educação e a munipalização do ensino como temas de estudos recentemente produzidos no Brasil. In: 29a Reunião Anual da Anped, 2006, Caxambu. 29a Reunião Anual da Anped - Educação, Cultura e Conhecimento na Contemporaneidade: Desafios e Compromissos. Caxambu: Anped, 2006.

\section{FEDERAÇÃO ASSOCIAÇÕES \\ INTERNACIONAL \\ DE DE BIBLIOTECÁRIOS E}

INSTITUIÇÕES - IFLA; ORGANIZAÇÃO DAS NAÇÕES UNIDAS PARA EDUCAÇÃO, CIÊNCIA E CULTURA - UNESCO. Manifesto IFLA/UNESCO para biblioteca escolar: a Biblioteca Escolar no Ensino e aprendizagem para todos. Paris: IFLA/UNESCO, 1999.

Diretrizes da IFLA/UNESCO para biblioteca escolar. São Paulo: IFLA/UNESCO, 2005. Tradução de Neusa Dias de Macedo e Helena Gomes de Oliveira.Disponível em: $<\quad$ http://www.ifla.org/files/assets/schoollibraries-resource-centers/publications/schoollibrary-guidelines/school-library-guidelines-pt_ br.pdf>. Acesso em 09 jan. 2016.

FIALHO, J. et al. Proposta para criação da rede estadual de bibliotecas escolares do estado de Goiás.In: CONGRESSO BRASILEIRO DE BIBLIOTECONOMIA, DOCUMENTAÇÃO E CIÊNCIA DA INFORMAÇÃO - CBBD, 25, 2013, [Anais eletrônicos...]. Florianópolis, SC: FEBAB, 2013.

FREY, K. Políticas públicas: um debate conceitual e reflexões referentes à prática da análise de políticas públicas no Brasil. Planejamento e Políticas Públicas, n. 21, jun. 2000. Disponível em: <http:// www.ipea.gov.br/ppp/index.php/PPP/article/ viewFile/89/158>. Acesso em: 20 dez. 2011.

FURTADO, D. A. Politicas públicas e biblioteca escolar: a realidade ludovicense. In: CONGRESSO BRASILEIRO DE BIBLIOTECONOMIA E DOCUMENTAÇÃO, 24., 2011, Anais... Maceió, 2011. Disponível em: <http://febab.org.br/ congressos/index.php/cbbd/xxiv/paper/ view/263/682>. Acesso em: 13 nov. 2012.

GARCEZ, E. F. O bibliotecário nas escolas: uma necessidade. Revista ACB: Biblioteconomia em Santa Catarina, Florianópolis, v.12, n.1, p.27-41, jan./jun., 2007.

GARCIA, R. C. Avaliação de Ações Governamentais: pontos para um começo de conversa. Brasília, IPEA/CENDEC, out., 1997.

GONZÁLEZ DE GOMEZ, M. N. Novos cenários políticos para a informação. Ci. Inf. Brasília, v.31, n.1, p.27-40, jan. /abr. 2002. 
HAIDAR, M. L. M.; TANURI, L. M. A evolução da educação básica no Brasil: política e organização. In.: MENESES, J. G.C. et al. Educação básica: políticas, legislação e gestão: leituras. São Paulo: Pioneira Thompson Learning, 2008.

HOWLETT, M.; RAMESH, M.; PERL, A. Política pública: seus ciclos e subsistemas: uma abordagem integral. Rio de Janeiro: Elsevier, 2013.

MAJONE, G.; WILDAVSKY, A. Implementation as evolution. In: PRESSMAN, J. L. \& WILDAVSKY, A.. Implementation. 3. ed. Berkeley: University of Califórnia.1984.

MUELLER, S. P. M. (Org.). Métodos para a pesquisa em Ciência da Informação. Brasília: Thesaurus, 2007.

NEVES, B. C. Políticas de informação, as tecnologias de informação e comunicação no âmbito da sociedade da informação. Revista Transinformação, Campinas, vol. 22, n.1, 2010. Disponível em: <http://periodicos.puccampinas.edu.br/seer/index.php/transinfo/ article/view/484/464>, Acesso em: 26 jul. 2016.

NEVES, B. C. Tecnologia e mediação: Curitiba: CRV, 2017.

OLIVEIRA, P. R. A biblioteca escolar na legislação da educação brasileira: trajetórias, ausências e presenças. Monografia (Bacharelado em Biblioteconomia) - Escola de Comunicações e Artes, Universidade de São Paulo, 2013. 160 f.

OliVEIRA, R. P. de; ADRIÃO, T. (Org.). Organização do ensino no Brasil: níveis e modalidades na Constituição Federal e na LDB. 2.ed. São Paulo: Xamã, 2007.

PEREIRA, A. K. Biblioteca na escola. Brasília: Ministério da Educação, Secretaria de Educação Básica, 2006. 57 p.

PEREIRA, M. O. Fundo da infância e adolescência - FIA: um estudo de caso na prefeitura de Maracá. 2014. 66 f. Monografia
( Bacharelado em Ciências Contábeis) Universidade do Extremo Sul Catarinense - UNESC, Criciúma, SC, 2014. Disponível em: $\quad<$ http://repositorio.unesc.net/ bitstream/1/3180/1/M\% C3 \% 81RCIA \% 20 DE\%20OLIVEIRA\%20PEREIRA.pdf $>$. Acesso em: 10 nov. 2015.

PERROTTI, E. Escola, biblioteca e promoção da Leitura. In.: _ Confinamento cultural, infância e leitura. São Paulo: Summus, 1990.p.6582.

PIERUCCINI, I. Infoeducação:

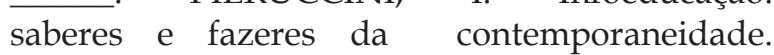
Blog Infoeducação USP, 2008. Disponivel em: <http://infoeducacaousp.blogspot.com. br/2008/10/infoeducao-saberes-e-fazeres-da. html>. Acesso em 10 jan. 2016.

Novos saberes para o século XXI. In: MENDONÇA, R.H.; MARTINS,M;F; (Orgs). Novos saberes para a Educação. Rio de Janeiro: ACERP; Brasília, DF: TV Escola, 2013. P. 9-25. Disponível em: <http://www2.eca.usp.br/ nucleos/colabori/documentos/vol_4_salto_ para_o_futuro_20_anos.pdf>. Acesso em 10 jan. 2016.

RIO DE JANEIRO. Projeto de Lei n. 597 de 30 de junho de 2015. Institui o Sistema Estadual de Bibliotecas Escolares do Estado do Rio de Janeiro. Rio de Janeiro: Assembleia Legislativa, 2015. Disponível em:< http://alerjln1.alerj.rj.gov.br/ scpro1519.nsf/1061f759d97a6b24832566ec0018d 832/58dcd8480a1e887b83257e7400625407? OpenDocument>. Acesso em 10 de jan. 2016.

RUA, M. G.. Políticas públicas. 2. ed. Florianópolis : Departamento de Ciências da Administração / UFSC, 2012. 128p.

ROMANINI, R. Para aprender políticas públicas: conceitos e teorias. Brasília, DF: IGEPP, 2013. 147 p.

SCHWARZELMÜLLER, A. R; GESTEIRA, I. A. L.; BULCÃO, M. Políticas públicas de informação no Brasil: Norte, Nordeste e Centro-Oeste. 
In: ENCONTRO NACIONAL DE ENSINO E PESQUISA EM INFORMAÇÃO - CINFORM, 5, 2004, Anais... Salvador, 2004. Disponível em: <http://dici.ibict.br/archive/>. Acesso em: 26 jul. 2011.

SECCHI, L. Políticas públicas: conceitos, esquemas de análise, casos práticos. São Paulo, Cengage Learning, 2010.

SILVA, G. A. C. da. Direito ao Desenvolvimento. São Paulo: Método, 2004.

SILVA, T. E. da. Política de informação na pósmodernidade: reflexões sobre ocaso do Brasil. Revista Informação \& Sociedade: Estudos, João Pessoa, v. 1, n. 1, 1991. Disponível em: <http:// www.informacaoesociedade.ufpb.br/119101. pdf>. Acesso em: 26 fev. 2016.

SILVA, J.D.O; CUNHA, J.A. O papel educativo da biblioteca escolar no context do plano nacional de educação. Encontros Bibli: revista eletrônica de biblioteconomia e ciência da informação, v. 21, n. 46, p. 45-58, mai./ago., 2016. ISSN 1518-2924. DOI: 10.5007/1518-2924.2016v21n46p45.

SOUZA, C. Políticas Públicas: uma revisão da literatura. Sociologias, Porto Alegre, ano 8, $\mathrm{n}^{\circ} 16$, jul./dez. 2006, p. 20-45. Disponível em: <http:// www.scielo.br/pdf/soc/n16/a03n16.pdf>. Acesso em 09 jan. 2016.

VIANA, L. Bibliotecas escolares: políticas públicas para a criação de possibilidades. São Paulo: USP, 2014. 167 f. il. Dissertação (Mestrado em Ciência da Informação) - Universidade de São Paulo, Escola de Comunicação e Artes, Programa de Pós-graduação em Ciência da Informação, São Paulo, 2014. Disponível em: <http://www. teses.usp.br/teses/disponiveis/27/27151/tde18122014-094444/pt-br.php>. Acesso em 10 jan. 2016.

VIEIRA, D. R. M. O bibliotecário como mediador da leitura: entre o livro e os usuários de três bibliotecas escolares públicas estaduais de Porto Alegre. 2012, 59 f. Monografia (Bacharelado em Biblioteconomia) - Universidade Federal do Rio Grande do Sul, Faculdade de Biblioteconomia e Comunicação, Porto Alegre, 2012. Disponível em: <https://www.lume.ufrgs. br/bitstream/handle/10183/69733/000872493. pdf?sequence=1>. Acesso em 10 jan. 2016.

WERSIG, G.; NEVELING, U. Os fenômenos de interesse para a Ciência da Informação, 1975. Tradução do inglês por Tarcísio Zandonade. Disponível em: http://www.alvarestech. com/lillian/GestaoDaInformacao/Rogerio/ WersigNeveling.pdf. Acesso em: 10 jul. 2016. 